\title{
Bringing the well being and patient safety research agenda together: why healthy HPs equal safe patients
}

\author{
Efharis Panagopoulou ${ }^{1}$, Anthony J. Montgomery ${ }^{2 *}$ and Evangelia Tsiga ${ }^{1}$ \\ ' Laboratory of Hygiene, Aristotle Medical School, Aristotle University of Thessaloniki, Thessaloniki, Greece \\ 2 Department of Education and Social Policy, University of Macedonia, Thessaloniki, Greece \\ ${ }^{*}$ Correspondence: monty5429@hotmail.com
}

Edited by:

Anat Drach-Zahavy, University of Haifa, Israel

Reviewed by:

Tilman Steinert, Centre for Psychiatry Suedwuerttemberg, Germany

Keywords: burnout, patient safety, employee health, health policy, organizational psychology

Health care is changing. Ageing populations, new therapeutic possibilities and rising expectations have made the provision of health care much more complex than in the past. The changing healthcare landscape means a greater burden for the healthcare professionals (HPs) who are expected to deliver the same quality of care with decreasing resources, while patient expectations of care remain stable or increase. Many countries in Europe are responding to this challenge by introducing new ways of delivering healthcare. However, the constant evolution of healthcare models is not resulting in better HPs, as indicated by the increasing phenomenon of burnout among health professionals (Leiter and Harvie, 1996; Rosenberg and Pace, 2006), or in safer care, as indicated by the increasing number of medical errors (Kondro, 2010). Today, there is enough evidence to suggest that expecting health professionals to deliver safe, efficient and patient-centered care, while they are getting more and more burnt-out, is not only ineffective but also costly and dangerous. In order for healthcare systems to be truly patient-centered, safe, and efficient, they need primarily to protect the health and well-being of their workers. Both healthcare professionals and patients are reinforced to view hospitals via a pathogenic lens. However, a saultogenic approach is needed. Interventions need to be bottom-up and system focused. Action research (AR) represents an appropriate methodology to link healthcare/patient input to improving hospital safety.

\section{HP AND PATIENT HEALTH ENTWINED}

One of the biggest risks for both patient safety and decreased quality of care today is health professionals themselves. Healthcare systems across Europe have systematically highlighted the importance of treating patients as whole people, not just as diseases, but health professionals (HPs) seem to be exempt from this holistic view. The European and Global trend is that between one third to half of health professionals are either feeling ill while present at work (i.e., presenteeism), or feel disengaged and demotivated (i.e., burnout) (Shanafelt et al., 2012). Substantial differences in burnout are observed by specialty, with the highest rates among HPs at the front line of care access (family medicine, internal, and emergency medicine). The consequences for HPs are significant and include; broken relationships, problematic alcohol use and suicidal ideation (Shanafelt et al., 2011; Oreskovich et al., 2012). The multi-center ORCAB (2014) project (http://orcab.web. auth.gr/) has recently shown that burntout HPs are at higher risk for medical mistakes. It has also highlighted that violence against HPs is increasing across Europe, especially women (European Foundation for the Improvement of Working and Living Conditions, 2010), and is driven by patient expectations and overburdened HPs. The aforementioned is exacerbated by increased patient expectations. Thus, a vicious cycle is created where inappropriate patient demands fuel feelings of exhaustion and depersonalization among HPs, which results in poor communication, which in turn ramps up already frustrated patient demands (and the cycle spirals downward).

\section{HEALTHCARE REFORMS HAVE OVERLOOKED THE HEALTH OF HEALTH PROFESSIONALS}

The inability to reap the full benefits from current investments in health care results, in many instances, from the difficulties of creating and maintaining an effective, efficient and motivated workforce. At the same time, all attempts to develop a European platform of objective indicators for assessment of health care have not included indicators related to HP burnout and well being. For example, the Euro Health Consumer Index (EHCI) 2013 is the seventh study conducted on European healthcare systems. The Index takes a consumer and patient perspective, and includes the following indicators: Patient rights and information, accessibility, outcome, range and reach of services provided, prevention, and pharmaceuticals. Yet the EHCI, similarly to the previous studies have not included indicators on HP well being. The aforementioned represents a system that is self-perpetuating and quite likely to continue, whereby small "fixes" mask the more fundamental change.

\section{POLICY MAKING DOES NOT INCLUDE ENOUGH EVIDENCE FROM FRONTLINE STAFF}

Both in the US and Europe, evidence indicates that top-down approaches dominate in healthcare. Healthcare initiatives, 
HP well-being

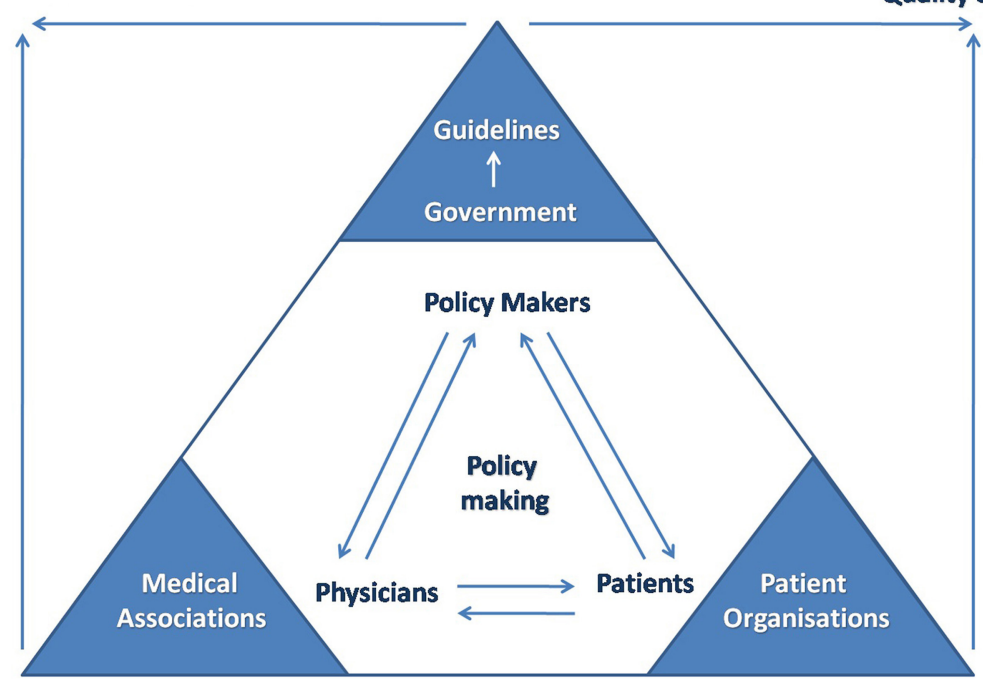

FIGURE 1 | Linking HP well-being and patient safety agenda.

changes or regulations are mainly developed by management boards, or policy making bodies with very little input from frontline staff or patients. This is also due to the fact that no systematic bottomup feedback mechanism exists between healthcare delivery and policy making. As a result the effectiveness of initiatives adopted through the top-bottom approach is limited. Even more worrying is the fact that physicians responsible for delivering care are not interested in contributing to design, policy or evaluation. For example, the majority of US physicians do not feel responsible for reducing healthcare costs (Tilburt et al., 2013), and interventions are dominated by nurse-led initiatives, while physician examples are seriously lacking (Montgomery et al., 2015).

\section{THE CHANGES THAT ARE NEEDED}

Medical associations have long been established with the goal of protecting, and supporting HPs in their professional role. Patient advocate organizations aim at supporting patients and promoting patient rights. Despite the fact that the ultimate goal of both types of organizations is to safeguard the quality of care, they still operate in parallel, or even against each other. We propose that Public, Patient, Professional Coalitions (3PCs) as an alternative governance mechanism, encouraging the participation of frontline staff, and patients, who have so far been largely sidelined from decision making in healthcare. For example, traditionally, patients contribute to service delivery via satisfaction surveys. We need to go beyond satisfaction surveys and involve the patients/public in rating indicators that are more directly linked to quality of care (e.g., presenteeism among HPs). There is considerable patient involvement in the planning and delivery of health services, but little evidence of the effect of this on quality and effectiveness of services (Crawford et al., 2002). Moreover, recent research indicates that there is currently insufficient evidence to be confident that the implementation of patient decision support interventions leads to systemwide savings (Walsh et al., 2014). This is more evidence of parallel (not integrated) tracks. The aforementioned is represented graphically in Figure 1.

\section{CONCLUSION}

Interventions linking staff and patient health to better safety will fail if they don't challenge established ways of behaving. AR, unlike other research approaches aimed at generating knowledge, focuses on facilitating action and generating knowledge about that action.

\section{REFERENCES}

Crawford, M. J., Rutter, D., Manley, C., Weaver, T., Kamaldeep, B., Fulop, N., and Tyrer, P.
(2002). Systematic review of involving patients in the planning and development of health. BMJ 325, 1263-1265. doi: 10.1136/bmj.325. 7375.1263

European Foundation for the Improvement of Working and Living Conditions. (2010). Physical and Psychological Violence at the Workplace. Available online at: http://eurofound.europa.eu/ sites/default/files/ef_files/pubdocs/2010/54/en/1/ EF1054EN.pdf

Kondro, W. (2010). Medical errors increasing because of complexity of care and breakdown in doctorpatient relationship, physician consultant says. CMAJ: 182, E645-E646. doi: 10.1503/cmaj.1093344

Leiter, M. P., and Harvie, P. L. (1996). Burnout among mental health workers: a review and a research agenda. Int. J. Soc. Psychiatry 42, 90-101. doi: 10.1177/00207640960 4200203

Montgomery, A., Doulougeri, K., and Panagopoulou, E. (2015). Implementing action research in hospital settings: a systematic review. J. Health Organ. Manage. 29.

ORCAB. (2014). Improving Quality and Safety in the Hospital: The Link Between Organisational Culture, Burnout and Quality of Care. Available online at: http://orcab.web.auth.gr/ [Accessed October 7, 2014].

Oreskovich, M. R., Kaups, K. L., Balch, C. M., Hanks, J. B., Satele, D., Sloan, J., et al. (2012). Prevalence of alcohol use disorders among American surgeons. Arch. Surg. 147, 168-174. doi: 10.1001/archsurg. 2011.1481

Rosenberg, T., and Pace, M. (2006). Burnout among mental health professionals: special considerations for the marriage and family therapist. J. Marital Fam. Ther. 32, 87-99. doi: 10.1111/j.1752-0606.2006. tb01590.x

Shanafelt, T. D., Balch, C. M., Dyrbye, L., Bechamps, G., Russell, T., Satele, D., et al. (2011). Special report: suicidal ideation among American surgeons. Arch. Surg. 146, 54-62. doi: 10.1001/archsurg.2010.292

Shanafelt, T. D., Boone, S., Tan, L., Dyrbye, L. N., Sotile, W., Satele, D., et al. (2012). Burnout and satisfaction with work-life balance among US physicians relative to the general US population. Arch. Intern. Med. 172, 1377-1385. doi: 10.1001/archinternmed. 2012.3199

Tilburt, J. C., Wynia, M. K., Sheeler, R. D., Thorsteinsdottir, B., James, K. M., Egginton, J. S., et al. (2013). Views of US physicians about controlling health care costs. JAMA 310, 380-388. doi: 10.1001/jama. 2013.8278

Walsh, T., Barr, P. J., Thompson, R., Ozanne, E., O'Neill, C., and Elwyn, G. (2014). Undetermined impact of patient decision support interventions on healthcare costs and savings: systematic review. BMJ 348:188 doi: 10.1136/ bmj.g188

Conflict of Interest Statement: The authors declare that the research was conducted in the absence 
of any commercial or financial relationships that could be construed as a potential conflict of interest.

Received: 14 October 2014; accepted: 11 February 2015; published online: 27 February 2015.

Citation: Panagopoulou E, Montgomery AJ and Tsiga

$E$ (2015) Bringing the well being and patient safety research agenda together: why healthy HPs equal safe patients. Front. Psychol. 6:211. doi: 10.3389/fpsyg. 2015.00211

This article was submitted to Psychology for Clinical Settings, a section of the journal Frontiers in Psychology. Copyright (c) 2015 Panagopoulou, Montgomery and Tsiga. This is an open-access article distributed under the terms of the Creative Commons
Attribution License (CCBY). The use, distribution or reproduction in other forums is permitted, provided the original author(s) or licensor are credited and that the original publication in this journal is cited, in accordance with accepted academic practice. No use, distribution or reproduction is permitted which does not comply with these terms. 